\title{
Importance of self-esteem for the parental couple: Testing for actor and partner
}

\author{
effects \\ Nahema El Ghaziri ${ }^{1}$, Joëlle Darwiche ${ }^{1}$, Jean-Philippe Antonietti ${ }^{1}$ and Ulrich Orth ${ }^{2}$ \\ ${ }^{1}$ University of Lausanne; ${ }^{2}$ University of Bern

\begin{abstract}
This article has been accepted for publication but has not been through the copyediting, typesetting, pagination, and proofreading process. This article may not exactly replicate the final, authoritative version published in the journal. It is not the copy of record. Please cite this article as follows:

El Ghaziri, N., Darwiche, J., Antonietti, J. P., \& Orth, U. (2021). Importance of self-esteem for the parental couple: Testing for actor and partner effects. Family Relations , 70, 1055-1072. https://doi.org/10.1111/fare.12532
\end{abstract}

\author{
Author Note \\ Nahema El Ghaziri, Family and Development Research Center, Institute of \\ Psychology, Faculty of Social and Political Sciences, University of Lausanne, Switzerland ; \\ Joëlle Darwiche, Family and Development Research Center, Institute of Psychology, \\ Faculty of Social and Political Sciences, University of Lausanne, Switzerland ; Jean- \\ Philippe Antonietti, Family and Development Research Center, Institute of Psychology, \\ Faculty of Social and Political Sciences, University of Lausanne, Switzerland ; Ulrich Orth, \\ Department of Psychology, University of Bern, Switzerland. \\ Correspondence concerning this article should be addressed to Nahema El \\ Ghaziri, Université de Lausanne, Institut de psychologie, Bâtiment Geopolis, CH- 1015 \\ Lausanne. \\ E-mail : nahema.elghaziri@gmail.com
}




\begin{abstract}
Objective: This study investigates the actor and partner effects of self-esteem on the quality of the parental couple relationships: the romantic relationship and the coparental relationship. The mediating role of romantic quality also is considered. Background: Previous findings suggest that self-esteem affects the quality of the romantic relationship. Yet, few studies have focused on the parental couple or explored the coparental relationship, which plays a significant role for the family unit. Method: Using data from two independent samples (including a total of 2,549 couples), actor-partner interdependence models (APIMs) were tested to analyze the effects of self-esteem on both relationships of the parental couple.

Results: Parents with high self-esteem reported higher romantic quality and as did their partner. Self-esteem also showed actor and partner effects on negative coparenting. Accordingly, parents with high self-esteem reported fewer conflicts about the child and fewer undermining behaviors. In contrast, the link between self-esteem and positive coparenting received little support. However, when mothers had high self-esteem, they engaged more frequently in positive coparental behaviors, such as including the father. Finally, romantic relationship quality mediated the actor and partner effects of selfesteem on negative coparenting. Conclusion: Having high self-esteem appears to be a couple resource with beneficial effects for both parents.

Implications: Improving parents' self-esteem could be an important gateway for enhancing the functioning of families with romantic and coparental difficulties. Keywords: coparenting, Couple/Marital/Romantic Relationships, Family strengths.
\end{abstract}


Importance of self-esteem for the parental couple: Testing for actor and partner effects

Individuals with high self-esteem appear to be advantaged when it comes to building and maintaining enriching relationships. The longitudinal meta-analysis by Cameron and Granger (2019) established the prospective effect of self-esteem on one's interpersonal life. In the family system, research has focused on the role of self-esteem for the romantic relationship. Findings highlight the dyadic effects of self-esteem and the importance of considering both partners. Accordingly, a meta-analysis by Erol and Orth (2017) indicated that self-esteem has both actor and partner effects, meaning that it is linked to the individual's romantic satisfaction (actor effect) but also to the individual's partner's satisfaction (partner effect). Furthermore, the existing longitudinal research support the fact that self-esteem predicts the development of the romantic satisfaction (Erol \& Orth, 2017).

Although extensive research has been carried out on self-esteem and the romantic relationship, its effects in the parental couple have been overlooked. First, research focusing on parents as couples is scarce and has led to mixed results (Culp \& Beach, 1998; Don \& Mickelson, 2014; El Ghaziri, Darwiche, \& Antonietti, 2019; Frosch, Mangelsdorf, \& McHale, 1998). Second, the parental couple is characterized by the fact that the partners are simultaneously engaged in two distinct relationships. The romantic relationship, only including the parents, and the coparental parental one, which refers to the way parents share the caring and raising of their children (McHale, 2007). Again, strikingly few studies have analyzed the effect of self-esteem on the coparental relationship.

Parenthood entails fundamental transformations for the couple, with enduring changes. Accordingly, the variables influencing the romantic relationship of parents and 
non-parents might differ. Also, the parental couple embodies the axis around which the other family relationships emerge and develop. As we will see, the literature highlights its predominant role in the well-being of each family member. Accordingly, enhancing the knowledge on this unique system could help refining therapeutic interventions and have beneficial repercussions on the whole family. In the present study, we examine the effects of parents' self-esteem on romantic satisfaction and adaptive coparenting. The actor and partner effects of self-esteem on the romantic and coparental relationships are analyzed as well as the paths linking those three variables, enabling an enriched perspective on the parental couple system.

In the following sections, we start by defining the parental couple and its different facets. We then address the importance of self-esteem for social bonds and more specifically for the romantic and coparental relationship. Finally, we highlight the value of considering the parental couple system as a whole, because of the potential spillover effects between the romantic and coparental relationships.

\section{The parental couple}

Having a child fundamentally changes the couple system as it involves multiple transformations for the individual and for the couple. This transition implies new responsibilities, a new social role and the development of a new relationship: the coparental one. Accordingly, couples who are parents seem to differ from couples who are not parents. In line with this perspective, the transition to parenthood has been linked to normative changes in mothers' self-esteem (van Scheppingen et al., 2018). Furthermore, literature repeatedly showed that parents report a less satisfying romantic relationship with a steeper decline of satisfaction across time (e.g., Holmes et al., 2013; Keizer \& Schenk, 2012). 
As aforementioned, the parental couple system is characterized by two distinct relationships, romantic and coparental. While the romantic relationship only involves the parents and concerns aspects such as love, sex, or finances (Minuchin, 1974), the coparental relationship includes the parents and the children. It refers to the ability of the partners to work as a team in their parental role (McHale, 2007). In these roles, do parents support, undermine, or compete with each other while raising their children? Furthermore, are parents able to coordinate their various parenting tasks? Noticeably, positive and negative coparenting are two distinct variables, meaning that one parent may be simultaneously supportive and intrusive to the partner (Kuo et al., 2017).

Empirical findings support the theoretical relevance of distinguishing between the romantic and coparental relationship. Indeed, previous literature reports that distress at the romantic level is not synonymous with distress at the coparental level: a couple can have disagreements at one level but may be well-functioning at the other level (McHale et al., 2000). Furthermore, construct validity analyses confirm that romantic and coparental quality ought to be considered separately (Van Egeren, 2004).

Both the romantic and coparental relationships are uniquely related to the wellbeing of parents and children. For example, the romantic quality was shown to affect the trajectory of partners' life happiness and depressive symptoms (Kamp Dush, Taylor, \& Kroeger, 2008). It also was significantly associated with parenting stress and mothers' parenting efficacy (Kersh et al., 2006). Furthermore, romantic satisfaction appears to be linked to children's internalizing and externalizing problems (Knopp et al., 2016; Murphy et al., 2017). As for the coparental quality, it was shown to be a source of psychological safety for parents (Schoppe-Sullivan et al., 2016), and compared to the romantic quality, coparental quality appears to be a more proximal predictor of children's well-being (Holland \& McElwain, 2013). Accordingly, in a meta-analysis by 
Teubert \& Pinquart (2010), it was shown that coparenting quality predicts change in children's adjustment and that the effects of coparenting persist after controlling for marital quality.

In summary, the quality of the romantic and coparental relationships are two distinct variables that cannot be deduced from one another and that significantly affect the development of each family member's well-being. As they represent different constructs, they might not have the same causes, correlates, or consequences (McHale, 1995). It is relevant, therefore, to consider both of these relationships in order to further understand the dynamics of the parental couple system.

\section{Self-esteem and social bonds}

Self-esteem refers to the way people perceive themselves, in their entirety (Rosenberg, 1965). According to Rosenberg's theory (1965), the importance of selfesteem for one's social life stems from the fact that we expect others to see us as we see ourselves. High self-esteem individuals expect positive regard from others, which facilitates sociability and restrains susceptibility. The sociometer theory takes a step forward and posits that self-esteem is an evolutionary system developed to maintain social interactions (MacDonald \& Leary, 2011). In this perspective, trait self-esteem is built upon childhood experiences and predicts the individuals' future social behaviors.

High self-esteem individuals have experienced acceptance, leading to the development of a sense of belongingness and allowing to approach others with serenity. Low self-esteem individuals on the other hand, have been through more rejection, leading them to develop defense mechanisms (i.e., unconscious psychological processes that explain a certain behavior, Cramer, 2000) in order to avoid further hurt. For 
example, low self-esteem individuals are expected to anticipate exclusion and to adopt a pessimistic perception in case of ambiguous cues.

\section{Self-esteem and the romantic relationship}

In order to understand the role of self-esteem for the quality of the romantic relationship, a compelling theory is the one elaborated through the risk regulation model (Murray et al., 1998). This model was developed specifically with the goal of understanding individuals' behaviors in their romantic relationships, and self-esteem is considered to have a central role.

The risk regulation model suggests that partners are constantly torn between their goals of connectedness and of self-protection, which cannot be achieved simultaneously. Choosing connectedness goals means adopting behaviors such as disclosing one's feelings. If the partner has an appropriate reaction, it promotes the relationship and comes with a feeling of being understood and loved. However, these behaviors are risky because the partner might not react in the expected way, leading to a feeling of rejection.

Consequently, adopting connectedness goals can only occur if the individual feels it is safe enough. The model suggests that the individual's self-esteem predicts this choice. As mentioned above, the defense mechanisms of low self-esteem individuals are exacerbated by previous hurtful experiences which makes them doubt the positive regard of their partner and orientate them toward self-protective goals (Murray et al., 2001). Low self-esteem individuals will have a tendency, therefore, to adopt behaviors such as withdrawal instead of disclosure, which in turn erodes the quality of the relationship (Murray et al., 2002). Low self-esteem also might modify the partner's 
behavior, as the partner may grow tired of the individual's insecurities (Murray et al., 2006). Accordingly, partner effects are expected also.

Consistent with this perspective, previous studies repeatedly found that a person's low self-esteem is associated with a less satisfying romantic relationships, as perceived by the individual and the partner (for a review see Erol \& Orth, 2017). Low self-esteem also tends to interfere with the development of the relationship, with a significant decrease in satisfaction across time (Orth et al., 2012). However, those results concern the general population.

Four studies exclusively sampled parents (Culp \& Beach, 1998; Don \& Mickelson, 2014; El Ghaziri et al., 2019 ; Frosch et al., 1998). Using cross-sectional data, two of these studies reported a significant correlation between parents' self-esteem and their perception of romantic satisfaction (Culp \& Beach, 1998; Frosch et al., 1998). Using longitudinal data, El Ghaziri et al. (2019) reported similar results: mothers' and fathers' self-esteem had a significant effect on the initial level of romantic quality. However, only mothers' self-esteem affected the trajectory of the romantic relationship. In the last study, which was also longitudinal, the effect of self-esteem on one's own romantic quality was not significant. However, mothers' low self-esteem predicted a steeper decline in father's romantic relationship quality (Don \& Mickelson, 2014). Thus, although few research studies have been conducted, the initial findings reported suggest that parents also benefit from high self-esteem.

Nevertheless, some differences may exist. For example, as reported in two studies, mothers' self-esteem may have a more important role compared to fathers' selfesteem (Don \& Mickelson, 2014; El Ghaziri et al., 2019), whereas this gender effect does not seem to appear when evaluating the general population (Mund et al., 2015). It is 
valuable, therefore, to verify whether the results from the general population are supported also in the specific context of the parental couple.

Hypothesis: Our first hypothesis is that self-esteem will have actor and partner effects on parents' romantic quality.

\section{Self-esteem and the coparental relationship}

Although the risk regulation model was developed for the understanding of the romantic relationship, the authors indicate that the model also may apply to other bonds (Murray et al., 2006). Accordingly, it may represent an enriching avenue to why and how self-esteem may affect the coparental relationship.

Here again, the behaviors adopted by parents with low self-esteem may be driven by self-protective goals, which may have negative consequences for the relationship. For example, after having a bad day with their child, parents with low self-esteem might prefer not to ask for support, because having their partner minimizing the problem or simply refusing to help would be too hard to face. Consequently, they might not disclose the difficulties encountered with their child and hinder the coordination between parents. Furthermore, the lack of trust in the other's positive regard, which drives low self-esteem individuals to prefer self-protective goals, does not only concern one's partner. Low self-esteem individuals also underestimate their child's love (DeHart et al., 2003). Parents with low self-esteem might fear that the child would prefer the other parent, which may guide them toward undermining and competitive coparental behaviors. For instance, they might override the rules set by the other parent to gain the child's love and appreciation. In a broader perspective, it might be harder for them to set limits to the child and to say no because rejection is more hurtful to them. This may also 
create coparental tensions (as agreed rules are not respected) and in turn, affect the other partner's coparenting. For example, s/he might get dismissive.

In line with these assumptions, only three studies have been found to analyze the link between self-esteem and coparenting report, and these studies report significant results. Parents with high self-esteem appear to engage more frequently in positive coparental behaviors (e.g., supporting the other parent) and less frequently in negative coparental behaviors (e.g., competing for the child's attention; Frosch et al., 1998; El Ghaziri et al., 2019; Lindsey et al., 2005). Based on those findings, our second hypothesis is that self-esteem will have actor and partner effects on the coparental quality.

\section{Self-esteem and the parental couple system, the spillover effects}

As highlighted by Minuchin (1974), who was the first to theorize the distinction between the romantic and coparental relationships, the family system is defined by high levels of interdependency, where relationships are interconnected (e.g., Gao et al., 2018). Accordingly, when studying the parental couple, it is important also to evaluate the links between its two relationships: romantic and coparental. Although distinct, these relationships seem to affect each other. Indeed, the coordination developed between partners in their romantic relationship appears to represent the basis on which coparental quality will be built.

Previous findings have established that couples facing difficulties at the romantic level are more prone to adopt detrimental coparenting behaviors (McHale, 2007). Research also indicates that romantic quality has actor and partner effects on coparenting (e.g., Lee et al., 2016; Liu \& Wu, 2016). Accordingly, romantic quality seems to have a spillover effect on coparenting, such that the quality of the former may influence the latter. In view of these dynamics, the whole parental couple system should 
be considered to gain a comprehensive understanding of its functioning. A longitudinal study adopted this perspective and the results indicated that mothers' self-esteem reduced the decline in romantic quality, which in turn attenuated the decline in coparental quality (El Ghaziri et al., 2019). Based on this finding, our third hypothesis is that the romantic quality will mediate the actor and partner effects of self-esteem on the coparental quality.

\section{Present research}

Previous literature emphasizes the role of self-esteem for social bonds, as well as the importance of the parental couple relationships for the well-being of the family. Yet, surprisingly few studies tried to grasp the role of self-esteem for a satisfying parental couple. Nevertheless, in a recent study with data spanning four years, El Ghaziri et al. (2019) found that self-esteem had a long-term effect on the parental couple relationships and showed that the romantic quality mediated the effect of self-esteem on coparenting. Accordingly, self-esteem seems to have a powerful effect on the parental couple. However, the mechanisms underlying those results were not yet tested.

In the present study, our aim is to take a step further in understanding the nature of self-esteem's effect. Is self-esteem an individual resource, only having an effect on the individual's own perception of the romantic and coparental relationships or could selfesteem be considered a couple asset, with positive implications for both partners? Accordingly, the goal of the present study is to provide a fine-grained analysis by investigating the perception of the parental couple relationships at the individual level and by analyzing the role of each parent's self-esteem. We, therefore, focus on the interdependence between partners by analyzing the actor and partner effects. 
Based on previous results (Erol \& Orth, 2013; Lindsey et al., 2005), we expect to find the following outcomes: As noted above, our first hypothesis is self-esteem will have actor and partner effects on the quality of the romantic relationship (Hypothesis 1). Further, we hypothesize that self-esteem will have actor and partner effects on negative coparenting (Hypothesis 2a) and on positive coparenting (Hypothesis 2b). Finally, we examine the links between the three variables and expect the romantic quality to mediate the actor and partner effects of self-esteem on coparental quality (Hypothesis 3).

To test these hypotheses, we analyzed two different datasets. The first dataset was derived from the German Family Panel (Brüderl et al., 2015), while the second was collected in Switzerland. Investigating two independent samples represents an advantage with regard to the generalizability of the results. Furthermore, the Swiss sample included a measure of positive coparenting (which was not the case in the German sample), allowing for a more comprehensive understanding of the role of selfesteem for the coparental relationship.

The findings of the present study will enhance the comprehension of the parental couple functioning, which is useful for both researchers and health professionals. By untangling the links between an individual variable (self-esteem) and relational outcomes (romantic and coparental quality) this study has the advantage of representing a bond between two distinct research fields: personality and family. For health practitioners, clarifying the links between those variables means having a better comprehension of the mechanisms that lead to detrimental behaviors in the romantic and coparental relationships. Accordingly, it may represent new working avenues for interventions aimed at helping distressed families. 


\section{Methods}

\section{Study 1}

\section{Participants.}

The sample was composed of 2,313 couples (both parents in each couple participated in the study). The data came from the German Family Panel pairfam, release 6.0 (Brüderl et al., 2015), which is described in Huinink et al. (2011) and is freely accessible to the scientific community (http://www.pairfam.de/en/data/). The sampling method is described in Brüderl et al. (2015).

Participants' data was gathered through interviews. We used data from Wave 2, which was the first wave that included the three variables of interest and was collected between 2009 and 2010. The couples selected were heterosexual, had at least one child, and the family lived together. The age of the mothers ranged from 17 to 47 years $\left(M_{\text {years }}\right.$ $\left.=33.91, S D_{\text {years }}=4.76\right)$. That of fathers ranged from 18 to 69 years $\left(M_{\text {years }}=36.80, S D_{\text {years }}\right.$ = 5.52). The younger child's age ranged from less than a year to 19.5 years $\left(M_{\text {years }}=4.70\right.$, $\left.S D_{\text {years }}=3.68\right)$. A large majority of the couples were married $(87.5 \%)$ and on average, they had been together for 12.2 years. Regarding their socioeconomic status, the average household net income was $2,913 €$ per month $(S D=1,857)$.

\section{Measures.}

Self-esteem. Three items derived from the Rosenberg Scale (Rosenberg, 1965) were used to evaluate the self-esteem of each parent. In one of them, the wording proposed by Rosenberg was maintained (On the whole, I am satisfied with myself), while in the other two, the meaning was kept but the wording was simplified (I like myself just the way I am, and I feel worthless at times). A 5-point Likert-type scale (1=not at all, $5=$ absolutely ) was used and the scores of the negative item were reversed. The alpha reliability was .75 for mothers and .71 for fathers. 
Romantic relationship quality. The Network of Relationships Inventory (adapted version; Furman \& Buhrmester, 1985) was used to evaluate the quality of the romantic relationship as perceived by each parent. It comprised four subscales: intimacy (e.g., frequency of Telling partner what you are thinking), esteem (e.g., frequency of Partner expresses recognition for what you've done), dominance (e.g., frequency of Partner makes you do things his/her way), and conflict (e.g., frequency of being Annoyed or angry with each other). Each subscale was composed of two items. Responses were measured using a 5-point Likert scale (1=never, 5=always). For the analyses the negative items (i.e., dominance and conflict) were reverse-scored. The alpha reliability across all eight items was .75 for mothers and .73 for fathers.

Coparenting. Three items adapted from the Parent Problem Checklist (Dadds \& Powell, 1991) were used to evaluate the coparenting quality of each parent. The items were: how often do you experience Differences of opinion regarding caring and parenting issues; how often do Discussions regarding caring and parenting issues end in fights; and how often One parent disregards rules set by the other. Thus, only negative coparenting was measured. Responses were measured using a 5-point Likert scale (1=never, 5=very often). The alpha reliability was .81 for mothers and .79 for fathers.

The measures used are summarized in Table 1.

\section{Study 2}

\section{Participants.}

The sample consisted of 236 heterosexual couples who lived together and had at least one child. Data were collected in the French-speaking part of Switzerland, between November 2014 and November 2016. Participants were mainly reached through flyers distributed in kindergartens and were asked to fill in a paper-pencil or an online questionnaire. Both parents participated and were specifically asked to complete the 
questionnaire on their own and not to consult each other. The sample size was based on the number of couples wherein both partners participated in the study.

Mothers' ages ranged from 25 to 46 years $\left(M_{\text {years }}=35.9, S D_{\text {years }}=4.23\right)$. Fathers' ages ranged from 24 to 66 years $\left(M_{\text {years }}=38.19, S D_{\text {years }}=5.60\right)$. The younger child's age ranged from less than a year to 12 years $\left(M_{\text {years }}=3.17, S D_{\text {years }}=2.34\right)$. A large majority of the couples were married (77.2\%) and on average they had been together for seven years. Of the participants, $69 \%$ of the mothers and $63 \%$ of the fathers had completed a college degree.

\section{Measures.}

Self-esteem. The Rosenberg Scale (1965) was used to evaluate the self-esteem of each parent. The questionnaire was composed of 10 items, three of which overlapped with the items used in Study 1 (e.g., At times I feel that I am no good at all; I am able to do things as well as most other people) and parents rated their responses on a 5-point Likert-type scale (1=not at all, 5=absolutely). The alpha reliability was .83 for mothers and .86 for fathers.

Romantic relationship quality. The Dyadic Adjustment Scale (DAS; Spanier, 1976) was used to evaluate the quality of the romantic relationship, as perceived by each parent. The questionnaire comprises 32 items evaluating consensus, satisfaction, cohesion, and expression of affection (e.g., extent of agreement between parents regarding leisure time interests and activities and ways of handling family finances). Response options vary, with the items being rated on three different Likert-type scales. The alpha reliability was .91 for mothers and .91 for fathers.

Coparenting quality. The Coparental Scale was used to evaluate the coparenting quality of each parent (McHale, 1997). It is composed of 11 items. The frequency of behaviors was measured through a 7-point Likert-type scale (1=absolutely never, 
7=almost constantly -at least once an hour). The items were divided into two subscales: negative and positive coparenting. Negative coparenting was evaluated through five items measuring conflict (e.g., How often in a typical week - when all 3 of you are together - do you argue with your partner regarding something the child has done?) and disparagement (e.g., How often in a typical week - when you are alone with your child - do you find yourself saying something clearly negative or disparaging about your partner to your child?). Positive coparenting was evaluated through six items measuring affection (e.g., How often in a typical week - when all 3 of you are together - do you show physical affection to your child?) and family integrity (How often in a typical week - when all 3 of you are together - do you say or do something to invite, facilitate, or promote an affectionate or pleasant interchange between your partner and this child). For mothers, the alpha reliability of positive and negative coparenting was .74 and .75., respectively. For fathers, the alpha reliability of positive and negative coparenting was .80 and .75 , respectively.

\section{Statistical Analyses}

The analyses were conducted using the open source R ( R development Core Team, 2016). Missing values were handled using maximum likelihood estimation. In the first sample, $17.6 \%$ of the mothers' data and $31.6 \%$ of the fathers' data was missing. In the second sample, $0.4 \%$ of mothers' data and $1.0 \%$ of fathers' data was missing.

Although the missing rates were relatively high in Sample 1, the assumption that the data were missing at random (MAR) was justified. As explained by Howell (2008, p.208) "Data are missing at random (MAR) if the probability of missing data on a variable (Y) is not a function of its own value after controlling for other variables in the design". Accordingly, in Sample 1, missing data were due mainly to two reasons: being a secondary respondent and being a man. The PAIRFAM database (from which Sample 1 
was drawn) is based on a primary respondent who is asked if his or her partner would also agree to participate. Among the missing data, $84.4 \%$ came from partners that declined the request to participate in the study. Furthermore, several findings highlight the fact that men are less likely to participate in research studies, compared to women (e.g., Galea \& Tracy, 2007). Accordingly, among the partners that refused to participate $69 \%$ were men. Based on these observations, there was reasons to expect that the missing data were due to the type of participant and to gender, and not to the values of the variables of interest.

The first step was to analyze the actor and partner interdependence models (APIM; Kenny \& Cook, 1999) using manifest variables and robust structural equation modeling through the lavaan package (Rosseel, 2011). This type of analyses was chosen as it was specially created to evaluate the interplay between partners and appropriately test for it. The dyads were heterosexual and therefore treated as distinguishable. Accordingly, the fit of the models was perfect but irrelevant (distinguishable APIMs are saturated, i.e., they have zero degrees of freedom).

The second step was to analyze an actor and partner interdependence mediation model (APIMeM; Ledermann \& Kenny, 2012). This model is similar to the APIM because it includes two actor and two partner effects. However, its specificity lies in the fact that it also includes two mediator variables (one for mothers and one for fathers). Each of the four actor and partner effects can be mediated by the two mediators. Consequently, there are eight possible indirect effects. To evaluate the significance of the indirect effects, we estimated the bias-corrected bootstrap of 95\% confidence intervals for the unstandardized effects. The confidence intervals were based on 1,000 bootstrap samples. 
Considering the complexity of the APIMeM, it was only evaluated in the first sample. As it is much larger than Sample 2 it assures greater power and thus higher precision of the results.

In order to assess whether romantic and coparental quality were distinct constructs, (i.e., capturing unique aspects of the parental couple), we calculated their discriminant validity. To that end, we used the heterotrait-monotrait ratio of correlations (HTMT; Henseler, Ringle, \& Sarstedt, 2015). Heterotrait correlations evaluate the relationship between items of different constructs, while monotrait correlations evaluate the relationship between items of the same construct. HTMT quantifies the difference between the averages of these two types of correlations. The smaller it is, the more the items of the same construct are related to one another and unrelated to the items of the other construct. In both studies, for mothers and fathers, the results confirmed that romantic and coparental quality were distinct constructs. Indeed, the HTMTs were all below 0.85, as recommended by Kline (2015). In Study 1, HTMT was 0.57 for mothers and 0.50 for fathers; in Study 2, HTMT was 0.66 for mothers and 0.58 for fathers. In Study 2, positive and negative coparenting were also found to be different constructs (for mothers HTMT = 0.23 and for fathers HTMT = 0.16).

The syntax for the analyses can be accessed via the subsequent link: https://osf.io/rzs24/?view_only=61c8a65a53184471927ed7d7d5232a4e

\section{Results}

\section{Preliminary Analyses}

Fathers had significantly higher self-esteem, compared to mothers (Study 1: $t(1361)=7.67, p<.001$; Study 2: $t(234)=2.29, p=.02)$. Mothers reported a higher romantic quality. However, the difference between partners was only significant in the first study (Study 1: $t(1338)=-5.81, p<.001$; Study 2: $t(235)=-0.43, p=.67$ ). Mothers 
also reported significantly more negative coparenting (Study 1: $t(1390)=-3.00, p<.01$; Study 2: $t(229)=-3.33, p<.01)$ and more positive coparenting (Study 2: $t(229)=-4.39$, $p<.001)$

Zero-order correlations indicated that partners had some similarities with each other regarding their level of self-esteem, romantic quality, and coparental quality (see Tables 1 and 2 in the appendices). The results also showed that for mothers and fathers, higher self-esteem was linked to enhanced romantic quality, less negative coparenting, and more positive coparenting. Additionally, having a partner with high self-esteem was also associated with the individual's greater perception of romantic quality and a lower level of negative coparenting. However, it was not linked to positive coparenting.

\section{Hypothesis 1: Does Self-Esteem Have Actor and Partner Effects on the Quality of}

\section{the Romantic Relationship?}

\section{Study 1.}

All actor and partner effects were significant (Figure 1). Mothers with high selfesteem reported a higher romantic quality $(\beta=.35, p<.001)$ and so did their partner $(\beta$ $=.19, p<.001$ ). Similarly, fathers' high self-esteem had a positive effect on both their own perception of romantic quality $(\beta=.23, p<.001)$ and the perception of their $\operatorname{partner}(\beta=.11, p<.001)$.

\section{Study 2.}

Again, all actor and partner effects of self-esteem were significant (Figure 1, to be placed about here). When mothers displayed high self-esteem, they perceived higher romantic quality $(\beta=.35, p<.001)$ and so did their partner $(\beta=.21, p<.001)$. Similarly, high self-esteem fathers perceived higher romantic quality $(\beta=.31, p<.001)$ and so did their partner $(\beta=.12, p=.023)$. 
Accordingly, the results of Study 1 and Study 2 fully supported the first hypothesis. Furthermore, in both studies, for mothers and fathers, the actor effects were of medium effect size, while the partner effects were of small effect size (Cohen, 1988).

\section{Hypothesis 2: Does Self-Esteem have Actor and Partner Effects on the Quality of the Coparental Relationship?}

Study 1.

Only negative coparenting was evaluated in this sample and self-esteem had significant actor and partner effects (Figure 2). When mothers had high self-esteem, they reported less negative coparenting $(\beta=-.23, p<.001)$ and so did their partner $(\beta=$ $-.17, p<.001)$. Similarly, when fathers had high self-esteem, they reported less negative coparenting $(\beta=-.18, p<.001)$ and so did their partner $(\beta=-.09 p=.001)$.

\section{Study 2.}

In this sample, negative and positive coparenting were evaluated. The analysis on negative coparenting showed actor effects for both parents (Figure 2, to be placed about here). Mothers and fathers with high self-esteem reported less negative coparenting (for mothers, $\beta=-.14, p=.028$, and for fathers, $\beta=-.23, p=.001)$. However, only one partner effect was significant: when fathers had high self-esteem, mothers reported less negative coparenting $(\beta=-.21, p=.002)$.

For positive coparenting, only mothers' actor effect was significant. When they had high self-esteem, they reported engaging more frequently in positive coparental behaviors $(\beta=.25, p<.001)$.

The second hypothesis was divided to examine negative and positive coparenting separately. Hypothesis 2a concerned negative coparenting and was largely supported by the results. Hypothesis $2 \mathrm{~b}$ concerned positive coparenting and self-esteem seemed to 
have a less important effect on the quality of this variable. All of the significant results were of small effect size.

\section{Hypothesis 3: Does the Romantic Quality Mediate the Actor and Partner Effects of}

\section{Self-Esteem on Coparenting Quality?}

The mediating effect of the romantic relationship quality was tested in Study 1.

Mothers' and fathers' romantic quality were significant mediators (Figure 3, to be placed about here). Indeed, the bootstrap intervals showed that all total indirect effects were significant (see Table 3 in appendices). Mothers' actor effect was mediated only by their own romantic quality ( $58.7 \%$ of the total effect), while fathers' actor effect was mediated by their own $(39.4 \%)$ and by their partner's $(6.1 \%)$ romantic quality. Similarly, mothers' partner effect was only mediated by their own romantic quality (50\%), while fathers' partner effect was mediated by their own romantic quality and by their partner's romantic quality (corresponding to $35.8 \%$ and $19.4 \%$, respectively, of the total effect). All direct effects remained significant with the exception of one. Mothers' partner effect was no longer significant.

The results were therefore in line with the third hypothesis and confirmed the importance of considering the whole parental couple system as spillover effects were found between the romantic and coparental relationships. Mothers' romantic quality appeared to have a central role as it mediated all actor and partner effects.

\section{Discussion}

This article aimed at gaining a better understanding of the role of self-esteem for family relationships, focusing on the parental couple. To that end, actor and partner effects were evaluated in two independent samples. As longitudinal effects have already been shown (El Ghaziri et al., 2019), the goal of the present research was to uncover the 
mechanisms that may cause and explain the fact that parents' self-esteem seems to affect the development of the romantic and coparental across time.

The risk regulation model suggests that self-esteem affects individuals' perception of their partner and relationship (Murray et al, 2001). While high self-esteem individuals tend to see things through a more positive lens, low self-esteem individuals, on the other hand, tend to focus on the negative aspects. Our results are in line with this perspective and indicate that higher self-esteem is associated with a more positive perception of the romantic relationship. The significant role of self-esteem for the romantic relationship also seems to arise from the fact that its effects spread from one partner to the other. Accordingly, when one of the parents had high self-esteem, both members of the couple seemed to benefit and reported a satisfying romantic relationship. Those results indicate a double effect of self-esteem, highlighting the fact that interdependency is one of the processes through which self-esteem may affect the trajectory of the romantic relationship. Noticeably, this is consistent with previous findings on the general population (Erol \& Orth, 2017)

Another contribution of the present article was to evaluate the effects of selfesteem on coparenting quality. On a theoretical perspective, as for the romantic relationship, parents with low self-esteem might doubt the positive regard of their partner and child (Murray et al, 2001). Consequently, they may be more sensitive to criticism and/or to the child's bad mood, thereby enhancing the risks of adopting unadjusted coparental behaviors and hindering the use of positive coparental behaviors. Again, our results confirm previous findings (Frosch et al., 1998; Lindsey et al., 2005) and indicate that self-esteem is an asset for the coparental relationship. Mothers and fathers in both samples reported less negative coparental behaviors when they reported 
higher self-esteem. Noticeably, in Study 1, both partner effects were significant also, whereas in Study 2 only fathers' self-esteem had an effect on mothers' coparenting.

The fact that mothers' self-esteem had an effect on fathers' negative coparenting in Study 1 but not in Study 2 could have several explanations. It could be a consequence of methodological differences. Indeed, the studies used different instruments to evaluate negative coparenting. Although both instruments evaluated conflict, in Study 2 the questionnaire also included items on disparagement, which may have affected the results. The discrepancy between the two studies could also be a result of cultural differences. Sample 1 was collected in Germany, while Sample 2 was collected in Switzerland. These two countries are similar in several aspects. However, gender equality seems less supported in Switzerland, as it displays a larger gender gap compared to Germany (Murphy \& Oesch, 2016; World Economic Forum, 2017). Consequently, fathers' representation of motherhood might not be the same in both countries. Swiss fathers might have a more traditional perception of mothers, considering them as the child's expert regardless of the mothers' feelings. As a consequence, mothers' self-esteem might not affect fathers' coparental behaviors and they might have a higher tendency to conform to mothers' opinion. In line with this assumption, a study on Swiss families reported that partners seem to adopt a more traditional functioning after the transition to parenthood; mothers usually taking in charge most of the duties related to the child (Benardi, Ryser, \& Le Goff, 2013). To further understand this difference between the two samples, it would be valuable to evaluate the perception of gender roles in both countries and its effect on coparental behaviors.

Self-esteem appeared to have a more marginal role on positive coparenting. Nevertheless, mothers with higher self-esteem reported engaging more frequently in 
positive coparenting behaviors, such as cooperation and support. Those results may have several explanations. According to Lindsey et al. (2005), having an optimistic perception of oneself may be linked to feeling more competent with the child, which in turn may lead to greater confidence in the partner's parental abilities.

Accordingly, it might be easier for high self-esteem mothers to trust their partner's child rearing abilities, and therefore to adopt cooperative coparental behaviors. On the other hand, having low self-esteem is linked to rejection experiences (Leary, Tambor, Terdal, \& Downs, 1995) and a child's love could be experienced as a booster of acceptance. For mothers with low self-esteem, it might be hard to share, leading to fewer positive coparental behaviors, such as including the father or promoting his relationship with the child. Accordingly, low self-esteem mothers appear to have a higher tendency to adopt gatekeeping behaviors, wherein they establish a distance between the father and the child (Gaunt, 2008). Finally, it is interesting to note that self-esteem was not linked to fathers' positive coparenting. Accordingly, the presence of low self-esteem (maternal or paternal) did not impede fathers' supportive coparental behaviors. As aforementioned, Swiss fathers seem to have a rather traditional family conception. This may orientate them toward supportive coparental behaviors because they recognize the mother as a the "reference", regardless of their level of self-esteem.

Conclusions

In summary, the analyses of the effects of self-esteem on coparenting indicated that parents with higher self-esteem report less coparental conflict and display less negative coparental behaviors, such as dismissing the other parent. Almost all partner effects also were significant. Thus, here again, an interdependency between partners 
was found, enhancing the importance of self-esteem for the parental couple. The effect of self-esteem on positive coparenting was weaker.

The difference between positive and negative coparenting could be linked to the moderating effect of risk. As demonstrated by Cameron and Granger (2019), in situations with high social risks (such as rejection), the differences between high and low self-esteem individuals are exacerbated. Conversely, when social risk is experimentally reduced, high and low self-esteem individuals display similar behaviors. It is likely that negative coparenting occurs in situations of tension, with a greater risk of rejection, implying marked differences in the behaviors adopted by high versus low selfesteem parents. Contrariwise, positive coparenting might occur in more peaceful moments, during which self-esteem has a less important effect, as indicated by our results.

As emphasized by the family systems theory (Minuchin, 1974), the romantic and coparental relationships are interdependent. Indeed, several studies have reported spillover effects from the romantic relationship to the coparental one (e.g., McHale, 2007). Based on these findings, we expected romantic quality to mediate the link between self-esteem and coparenting quality. The results confirmed our hypothesis. Accordingly, the fact that low self-esteem individuals adopt more negative coparental behaviors was partly explained by the fact that they have a more negative image of their romantic relationship. Thus, the disadvantages that low self-esteem represents for the family system should be taken seriously, as it appears to have cascading effects: unsurprisingly, experiencing tensions at the romantic level makes it more complicated to adopt considerate behaviors when it comes to coparenting. Spillover effects therefore represent a second mechanism explaining why and how self-esteem may affect the parental couple. 
Noticeably, most direct effects remained significant, meaning that the negative consequences of low self-esteem for coparenting quality should not be reduced to the repercussions of a low romantic quality.

Finally, it is interesting to note that there were differences between mothers and fathers. Indeed, mothers' romantic relationship quality was a mediator for all actor and partner effects, while fathers' romantic relationship quality only mediated their own actor and partner effects. Although mentalities are changing this might indicate that mothers still have a predominate role in the family system. On a clinical perspective, it emphasizes the importance of working on the mother's self-esteem as it is generally lower than the one of men (e.g., Kling, Hyde, Showers, \& Buswell, 1999) and appears to have multiple repercussions for herself, her partner, and in both the romantic and coparental relationships.

\section{Limitations}

Regarding the samples, in both studies, most participants came from a medium to high socio-economic background. Therefore, the generalizability of the results could be questioned. The effects of self-esteem might differ according to the background. For instance, low self-esteem could represent a further factor of vulnerability and the differences between high and low self-esteem individuals may be exacerbated in presence of intensified pressure. However, the fact that samples were collected in different countries and led to similar results strengthens confidence in the robustness of the findings. Another limitation is that we focused on heterosexual parents. It would be interesting to test whether the findings replicate in other parental constellations, such as same-sex parental couples.

Moreover, in both studies, only self-report measures were available, which represents a potential method bias. As highlighted by Orth (2013), when using only self- 
report measures the actor effect is based on the reports of one person, while the partner effect is based on the report of both partners (e.g., one partners' self-esteem and the other partner's perception of the romantic quality). Consequently, the measures used to evaluate the actor effect have more method variance in common compared to the measures used to evaluate the partner effect. This could bias the results, inflating or deflating them. In order to avoid this bias, variables should be assessed by multiple methods (using data from different sources). Accordingly, Orth (2013) evaluated the effects of personality on romantic satisfaction and found that when using both self and partner reports, the actor and partner effects were similar in size. When using only selfreport measures, the partner effect was deflated. A similar bias might have occurred in the present study and the true partner effects might be stronger.

The mediation effects were only tested in Study 1 because larger samples provide greater power and precision of the findings. However, the results should still be considered with caution. Indeed, Maxwell, Cole, \& Mitchell (2011) highlight the possibility of biases when evaluating mediation with cross-sectional data. For example, evaluating cross-sectional mediation may lead to significant results that might be inexistent once considering the longitudinal process. In the case of Study 1 , mediation effects were already shown with the same dataset using longitudinal analyses instead of APIMeM (El Ghaziri, et al., 2019), thereby strengthening confidence in the present results.

Finally, in the present study, self-esteem is considered as the independent variable. This choice was made for two reasons. First, self-esteem is a relatively stable characteristic of individuals, and previous findings suggest that the level of stability is similar to the Big Five personality traits (Kuster \& Orth, 2013). Second, longitudinal studies report that self-esteem is a predictor of social relationship quality rather than 
vice-versa (Cameron \& Granger, 2019). Nevertheless, it is possible that having enriching parental couple relationships also influences self-esteem.

\section{Conclusion}

The findings of this study indicate that high self-esteem has multiple positive effects on the parental couple and is profitable for both the romantic and the coparental relationships. Furthermore, both partners appear to benefit from an individual's high self-esteem. Studying self-esteem in conjunction with the coparental relationship is still a novelty but the results are promising and, given the importance of this relationship for family members (e.g., Don \& Mickelson, 2014) and family interactions (e.g., Le et al., 2016), further research would be useful. For example, on a theoretical perspective, it would be interesting to test the risk regulation model (Murray, Holmes, et al., 2006). Indeed, regarding the romantic relationship, it has been shown that self-esteem allows confidence in the partner's love, which is necessary to adopt relationship-oriented goals (Murray \& Holmes, 2011). In the coparental relationship, the felt security regarding the partners' and the child's love could interact to predict fulfilling coparental behaviors. Evaluating these aspects would help us further understand the paths through which self-esteem affects family relationships.

Implications

The present study enhances our knowledge regarding the resource that high selfesteem may represent for the parental couple. In future research, longitudinal data with long time spans should be considered. This would be helpful as romantic and coparental quality may change across time. For instance, the coparental relationship evolves as a function of the child's developmental stage, and the effect of self-esteem might change accordingly. For example, adolescence is a developmental stage at which the child must develop their autonomy more strongly and might show more rejecting behaviors. 
Conflicts between adolescents and parents could be particularly challenging for parents with low self-esteem and, consequently, could have detrimental effects on the coparental relationship, especially if the other parent devalues the perceived difficulties.

For practitioners, these results indicate that acknowledging the difficulties generated by low self-esteem and working on improving those issues could be an important gateway for families with romantic and/or coparental difficulties. Developing the parents' feeling of worth and their security in their partner and child's love, may lead to positive cascading results. Both partners could benefit from such an intervention and the positive repercussions on the romantic quality are expected to spillover coparenting. Such an intervention could be helpful for the whole family system and would be an interesting add-on to prevention and therapeutic programs focusing on the parental couple relationships (e.g., family foundations, Feinberg et al., 2016; enhanced triple P, Ireland, Sanders \& Markie-Dodds, 2003). For example, teaching couples to adequately support each other based on their self-esteem level could have beneficial effects. Indeed, due to their insecurities, low self-esteem individuals tend to be insensitive to certain types of support (Marigold, Cavallo \& Hirniak, 2019). This is problematic for both the receiver and the giver as the former feels neglected, while the latter feels unrecognized for the efforts done, which may discourage from further supportive behaviors.

Our findings also suggest that an intervention focused on self-esteem (e.g., Mruk, 2006) should help with the issues encountered at the romantic and coparental levels even if those problems were not addressed directly. This is an important advantage for those families where communication is highly problematic and where the conflict is fueled by each interaction between partners. Indeed, it would represent an indirect way to start enhancing the quality of the parental couple relationships. 


\section{References}

Benardi, L., Ryser, V.-A., \& Le Goff, J.-M. (2013). Gender role-set, family orientations, and women's fertility intentions in Switzerland. Swiss Journal of Sociology, 39, 9-31.

Brüderl, J., Schmiedeberg, C., Castiglioni, L., Arrànz Becker, O., Buhr, P., Fuß, D., . . . Schumann, N. (2015). The German Family Panel: Study design and cumulated field report (waves 1 to 6): Release 6.0 (Tech. Rep. No. 6.0).

http://www.pairfam.de/fileadmin/user_upload/redakteur/publis/Dokumentati on/TechnicalPapers/TP01_Field-Report_pairfam6.0.pdf

Buscaglia, L. (1972). Love. New York, NY: Fawcett Crest.

Cameron, J., \& Granger, S. (2019). Does self-esteem have an interpersonal imprint beyond self-reports? A meta-analysis of self-esteem and objective interpersonal indicators. Personality and Social Psychology Review, 23, 73-102. doi:

\section{$10.1177 / 1088868318756532$}

Cohen, J. (1988). Statistical power analysis for the behavioral sciences 2 nd edn. Hillsdale, NJ: Erlbaum.

Cramer, P. (2000). Defense mechanisms in psychology today: Further processes for adaptation. American Psychologist, 55, 637-646. https://doi.org/10.1037/0003066X.55.6.637

Dadds, M.R., \& Powell, M.B. (1991). The relationship of interparental conflict and global marital adjustment to aggression, anxiety, and immaturity in aggressive and nonclinic children. Journal of Abnormal Child Psychology, 19, 553-567. doi: 10.1007/BF00925820

DeHart, T., Murray, S.L., Pelham, B.W., \& Rose, P. (2003). The regulation of dependency in parent-child relationships. Journal of Experimental Social Psychology, 39, 5967. doi: 10.1016/S0022-1031(02)00511-5 
Delicate, A., Ayers, S., \& McMullen, S. (2018). A systematic review and meta-synthesis of the impact of becoming parents on the couple relationship. Midwifery, 61, 88-96. doi: 10.1016/j.midw.2018.02.022

Don, B.P., \& Mickelson, K.D. (2014). Relationship satisfaction trajectories across the transition to parenthood among low-risk parents. Journal of Marriage and Family, 76, 677-692. doi: 10.1111/jomf.12111

El Ghaziri, Nahema, Darwiche, Joëlle, \& Antonietti, Jean-Philippe. (2019). Is self-esteem a resource for the parental couple? A longitudinal study on the quality of the romantic and coparental relationships. Journal of Social and Personal Relationships. doi: 10.1177/0265407519838349

Erol, R.Y., \& Orth, U. (2013). Actor and partner effects of self-esteem on relationship satisfaction and the mediating role of secure attachment between the partners. Journal of Research in Personality, 47, 26-35. doi: 10.1016/j.jrp.2012.11.003

Erol, R.Y., \& Orth, U. (2017). Self-esteem and the quality of romantic relationships. European Psychologist, 21, 274-283. doi: 10.1027/1016-9040/a000259

Feinberg, M.E. (2003). The internal structure and ecological context of coparenting: A framework for research and intervention. Parenting: Science and Practice, 3, 95131. doi: 10.1207/S15327922PAR0302_01

Feinberg, M.E., Jones, D.E., Hostetler, M.L., Roettger, M.E., Paul, I.M. \& Ehrenthal, D.B. (2016). Couple-Focused Prevention at the Transition to Parenthood, a Randomized Trial: Effects on Coparenting, Parenting, Family Violence, and Parent and Child Adjustment. Prevention Science, 17, 751-764. doi:10.1007/s11121-0160674-z 
Fivaz-Depeursinge, E. (2008). Infant's triangular communication in "two for one" versus "two against one" family triangles: Case illustrations. Infant Mental Health Journal, 29, 189-202. doi: 10.1002/imhj.20174

Frosch, C.A., Mangelsdorf, S.C., \& McHale, J.L. (1998). Correlates of marital behavior at 6 months postpartum. Developmental Psychology, 34, 1438-1449. doi: $10.1037 / 0012-1649.34 .6 .1438$

Furman, W., \& Buhrmester, D. (1985). Children's perceptions of the personal relationships in their social networks. Developmental Psychology, 21, 1016-1024. doi: 10.1037/0012-1649.21.6.1016

Galea, S., \& Tracy, M. (2007). Participation Rates in Epidemiologic Studies. Annals of Epidemiology, 17, 643-653. doi:10.1016/j.annepidem.2007.03.013

Gao, M. M., Du, H., Davies, P. T., \& Cummings, E. M. (2018). Marital Conflict Behaviors and Parenting: Dyadic Links Over Time. Family Relations, 68, 135-149. doi:10.1111/fare.12322

Gaucher, D., Wood, J.V., Stinson, D.A., Forest, A.L., Holmes, J.G., \& Logel, C. (2012). Perceived regard explains self-esteem differences in expressivity. Personality and Social Psychology Bulletin, 38, 1144-1156. doi: 10.1177/0146167212445790

Gaunt, R. (2008). Maternal gatekeeping antecedents and consequences. Journal of Family Issues, 29, 373-395. doi: 10.1177/0192513X07307851

Henseler, J., Ringle, C.M., \& Sarstedt, M. (2015). A new criterion for assessing discriminant validity in variance-based structural equation modeling. Journal of the Academy of Marketing Science, 43, 115-135. doi: 10.1007/s11747-014-0403-8

Holland, A.S., \& McElwain, N.L. (2013). Maternal and paternal perceptions of coparenting as a link between marital quality and the parent-toddler relationship. Journal of Family Psychology, 27, 117-126. doi: 10.1037/a0031427 
Holmes, E. K., Sasaki, T., \& Hazen, N. L. (2013). Smooth Versus Rocky Transitions to Parenthood: Family Systems in Developmental Context. Family Relations, 62, 824-837. doi:10.1111/fare.12041

Howell, D.C. (2008) The analysis of missing data. In Outhwaite, W. \& Turner, S. Handbook of Social Science Methodology. London, England: Sage.

Huinink, J., Brüderl, J., Nauck, B., Walper, S., Castiglioni, L., \& Feldhaus. (2011). Panel analysis of intimate relationships and family dynamics (pairfam): Conceptual framework and design. Zeitschrift für Familienforschung, 23, 77-101.

Ireland, J., Sanders, M., \& Markie-Dodds, C. (2003). The impact of parent training on marital functioning: a comparison of two group versions of the triple p-positive parenting program for parents of children with early-onset conduct problems. Behavioural and Cognitive Psychotherapy, 31, 127-142. doi:10.1017/S1352465803002017

Kamp Dush, C. M., Taylor, M. G., \& Kroeger, R. A. (2008). Marital Happiness and Psychological Well-Being Across the Life Course. Family Relations, 57, 211-226. doi:10.1111/j.1741-3729.2008.00495.x

Keizer, R., \& Schenk, N. (2012). Becoming a parent and relationship satisfaction: A longitudinal dyadic perspective. Journal of Marriage and Family, 74, 759-773. doi: 10.1111/j.1741-3737.2012.00991.x

Kenny, D.A., \& Cook, W. (1999). Partner effects in relationship research: Conceptual issues, analytic difficulties, and illustrations. Personal Relationships, 6, 433-448. doi: 10.1111/j.1475-6811.1999.tb00202.x

Kersh, J., Hedvat, T. T., Hauser-Cram, P., \& Warfield, M. E. (2006). The contribution of marital quality to the well-being of parents of children with developmental 
disabilities. Journal of Intellectual Disability Research, 50, 883-893.

doi:10.1111/j.1365-2788.2006.00906.x

Kline, R.B. (2015). Principles and practice of structural equation modeling. New York, NY: Guilford Press.

Kling, K.C., Hyde, J.S., Showers, C.J., \& Buswell, B.N. (1999). Gender differences in selfesteem: A meta-analysis. Psychological Bulletin, 125, 470-500. doi: $10.1037 / / 0033-2909.125 .4 .470$

Kuo, P.X., Volling, B.L., \& Gonzalez, R. (2017). His, hers, or theirs? Coparenting after the birth of a second child. Journal of Family Psychology, 31, 710-720. doi: $10.1037 /$ fam 0000321

Kuster, F., \& Orth, U. (2013). The Long-Term Stability of Self-Esteem: Its time-dependent decay and nonzero asymptote. Personality and Social Psychology Bulletin, 39, 677-690. doi:10.1177/0146167213480189

Le, Y., McDaniel, B.T., Leavitt, C.E., \& Feinberg, M.E. (2016). Longitudinal associations between relationship quality and coparenting across the transition to parenthood: A dyadic perspective. Journal of Family Psychology, 30, 918-926. doi: $10.1037 /$ fam 0000217

Leary, M.R., Tambor, E.S., Terdal, S.K., \& Downs, D.L. (1995). Self-esteem as an interpersonal monitor: The sociometer hypothesis. Journal of Personality and Social Psychology, 68, 518-530. doi: 10.1037/0022-3514.68.3.518

Ledermann, T., \& Kenny, D.A. (2012). The common fate model for dyadic data: Variations of a theoretically important but underutilized model. Journal of Family Psychology, 26, 140-148. doi: 10.1037/a0026624

Lindsey, E.W., Caldera, Y., \& Colwell, M. (2005). Correlates of coparenting during infancy. Family Relations, 54, 346-359. doi: 10.1111/j.1741-3729.2005.00322.x 
Liu, C., \& Wu, X.c. (2016). Dyadic effects of marital satisfaction on coparenting in chinese families: Based on the actor-partner interdependence model. International Journal of Psychology 53, 210-217. doi: 10.1002/ijop.12274

MacDonald, G., \& Leary, M.R. (2011). Individual differences in self-esteem. In M. R. Leary \& J. P. Tangney (Eds.), Handbook of self and identity. New York, NY: Guilford Press.

Maxwell, S. E., Cole, D. A., \& Mitchell, M. A. (2011). Bias in Cross-Sectional Analyses of Longitudinal Mediation: Partial and Complete Mediation Under an Autoregressive Model. Multivariate Behavioral Research, 46, 816-841. doi:10.1080/00273171.2011.606716

McCarthy, M.H., Wood, J.V., \& Holmes, J.G. (2017). Dispositional pathways to trust: Selfesteem and agreeableness interact to predict trust and negative emotional disclosure. Journal of Personality and Social Psychology, 113, 95-116. doi: $10.1037 /$ pspi0000093

McHale, J.P. (1995). Coparenting and triadic interactions during infancy: The roles of marital distress and child gender. Developmental Psychology, 31, 985-996. doi: 10.1037//0012-1649.31.6.985

McHale, J.P. (1997). Overt and covert coparenting processes in the family. Family Process, 36, 183-201. doi: 10.1111/j.1545-5300.1997.00183.x

McHale, J.P. (2007). When infants grow up in multiperson relationship systems. Infant Mental Health Journal, 28, 370-392. doi: 10.1002/imhj.20142

McHale, J.P., Kuersten-Hogan, R., Lauretti, A., \& Rasmussen, J.L. (2000). Parental reports of coparenting and observed coparenting behavior during the toddler period. Journal of Family Psychology, 14, 220-236. doi: 10.1037/0893-3200.14.2.220

McHale, J.P., \& Rasmussen, J.L. (1998). Coparental and family group-level dynamics during infancy: Early family precursors of child and family functioning during 
preschool. Development and Psychopathology, 10, 39-59. doi:

\section{$10.1017 / S 0954579498001527$}

Minuchin, S. (1974). Families and family therapy. Cambridge, MA: Harvard University Press.

Mruk, C.J. (2006). Self-esteem, research, theory, and practice: Toward a positive psychology of self-esteem (3rd ed.). New York, NY: Springer

Murphy, E., \& Oesch, D. (2016). The Feminization of Occupations and Change in Wages: A Panel Analysis of Britain, Germany, and Switzerland. Social Forces, 94, 12211255. doi:10.1093/sf/sov099

Murphy, S.E., Boyd-Soisson, E., Jacobvitz, D.B. \& Hazen, N.L. (2017), Dyadic and Triadic Family Interactions as Simultaneous Predictors of Children's Externalizing Behaviors. Family Relations, 66: 346-359. doi:10.1111/fare.12225

Murray, S.L., Griffin, D.W., Rose, P., \& Bellavia, G. (2006). For better or worse? Selfesteem and the contingencies of acceptance in marriage. Personality and Social Psychology Bulletin, 32, 866-880. doi: 10.1177/0146167206286756

Murray, S.L., \& Holmes, J.G. (2011). Interdependent minds: The dynamics of close relationships. New York, NY: Guilford Press.

Murray, S.L., Holmes, J.G., \& Collins, N.L. (2006). Optimizing assurance: The risk regulation system in relationships. Psychological Bulletin, 132, 641-666. doi: 10.1037/0033-2909.132.5.641

Murray, S.L., Holmes, J.G., Griffin, D.W., Bellavia, G., \& Rose, P. (2001). The mismeasure of love: How self-doubt contaminates relationship beliefs. Personality and Social Psychology Bulletin, 27, 423-436. doi: 10.1177/0146167201274004

Murray, S.L., Holmes, J.G., MacDonald, G., \& Ellsworth, P.C. (1998). Through the looking glass darkly? When self-doubts turn into relationship insecurities. Journal of 
Personality and Social Psychology, 75, 1459-1480. doi: 10.1037/00223514.75.6.1459

Murray, S.L., Rose, P., Bellavia, G.M., Holmes, J.G., \& Kusche, A.G. (2002). When rejection stings: How self-esteem constrains relationship-enhancement processes. Journal of Personality and Social Psychology, 83, 556-573. doi: 10.1037/00223514.83.3.556

Orth, U. (2013). How large are actor and partner effects of personality on relationship satisfaction? The importance of controlling for shared method variance. Personality and Social Psychology Bulletin, 39, 1359-1372. doi: $10.1177 / 0146167213492429$

Orth, U., Robins, R.W., \& Widaman, K.F. (2012). Life-span development of self-esteem and its effects on important life outcomes. Journal of Personality and Social Psychology, 102, 1271-1288. doi: 10.1037/a0025558

R Core Team (2016). R: A language and environment for statistical computing. $\mathrm{R}$ Foundation for Statistical Computing, Vienna, Austria. URL http://www.Rproject.org/.

Román, S., Cuestas, P.J., \& Fenollar, P. (2008). An examination of the interrelationships between self-esteem, others' expectations, family support, learning approaches and academic achievement. Studies in Higher Education, 33, 127-138. doi: $10.1080 / 03075070801915882$

Rosenberg, M. (1965). Society and the adolescent self image. Princeton, NJ: Princeton University Press.

Rosseel, Y. (2011). Lavaan: An r package for structural equation modeling and more Journal of Statistical Software, 48, 1-36. doi: 10.18637/jss.v048.i02 
Schnarch, D. (2009). Passionate marriage: Keeping love and intimacy alive in committed relationships. New York, NY: Norton \& Company.

Schoppe-Sullivan, S.J., Settle, T., Lee, J.-K., \& Kamp Dush, C.M. (2016). Supportive coparenting relationships as a haven of psychological safety at the transition to parenthood. Research in Human Development, 13, 32-48. doi:

$10.1080 / 15427609.2016 .1141281$

Spanier, G.B. (1976). Measuring dyadic adjustment: New scales for assessing the quality of marriage and similar dyads. Journal of Marriage and the Family, 38, 15-28. doi: $10.2307 / 350547$

Stright, A.D., \& Bales, S.S. (2003). Coparenting quality: Contributions of child and parent characteristics. Family Relations, 52, 232-240. doi: 10.1111/j.17413729.2003.00232.x

Swann, W.B. (2012). Self-verification theory. In P. A. M. van Lange, A. W. Kruglanski \& E. T. Higgins (Eds.), Handbook of theories of social psychology (Vol. 2, pp. 23-42). Thousand Oaks, CA: Sage.

Teubert, D., \& Pinquart, M. (2010). The association between coparenting and child adjustment: A meta-analysis. Parenting: Science and Practice, 10, 286-307. doi: $10.1080 / 15295192.2010 .492040$

Van Egeren, L.A. (2004). The development of the coparenting relationship over the transition to parenthood. Infant Mental Health Journal, 25, 453-477. doi: 10.1002/imhj.20019

van Scheppingen, M.A., Denissen, J.J.A., Chung, J.M., Tambs, K., \& Bleidorn, W. (2018). Self-esteem and relationship satisfaction during the transition to motherhood. Journal of Personality and Social Psychology, 114, 973-991. doi: $10.1037 /$ spp0000156 
World Economic Forum (2017). The Global Gender Gap Report. Geneva, Switzerland:

World Economic Forum. 
Figure 1. Actor-partner interdependence model of self-esteem (SE) on romantic quality (RQ). Results of Study 1 are displayed before the slash and results of Study 2 are displayed after it. The figure shows standardized estimates. ${ }^{*} p<.05$.

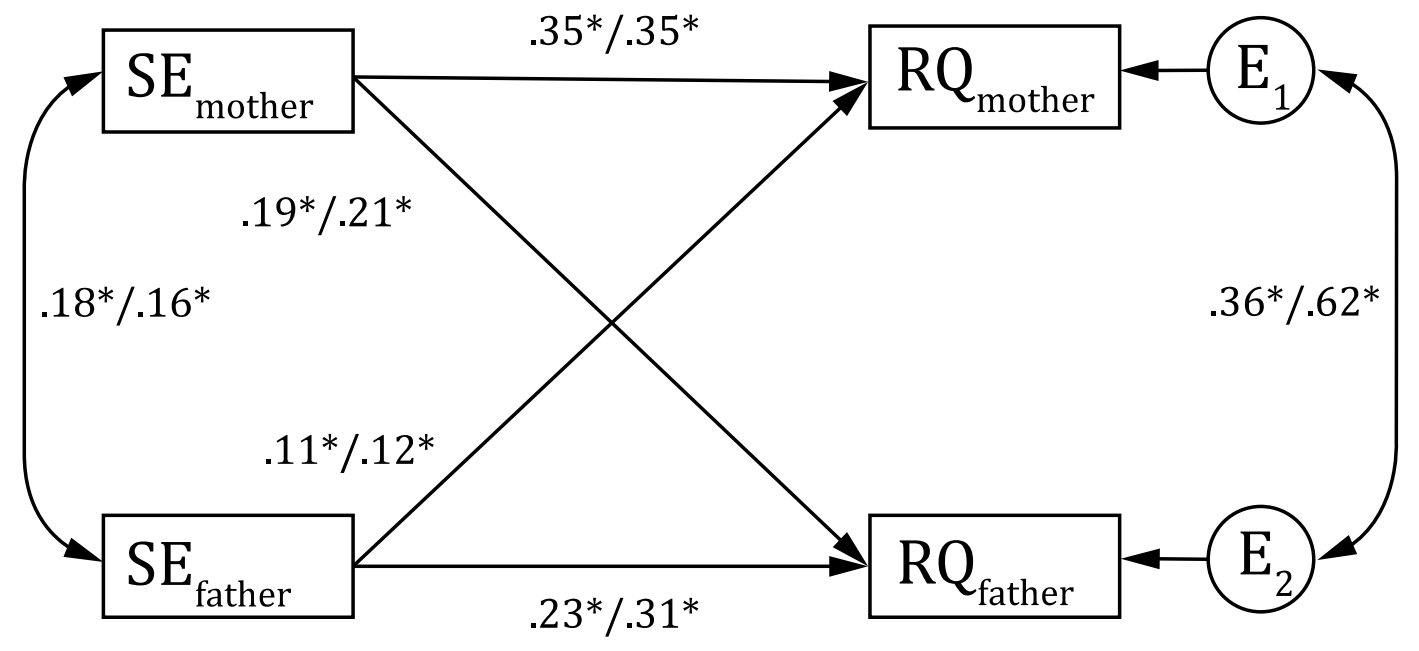

Figure 2. Actor-partner interdependence model of self-esteem (SE) on negative coparenting (NC). Results of Study 1 are displayed before the slash and results of Study 2 are displayed after it. The figure shows standardized estimates. $* p<.05$.

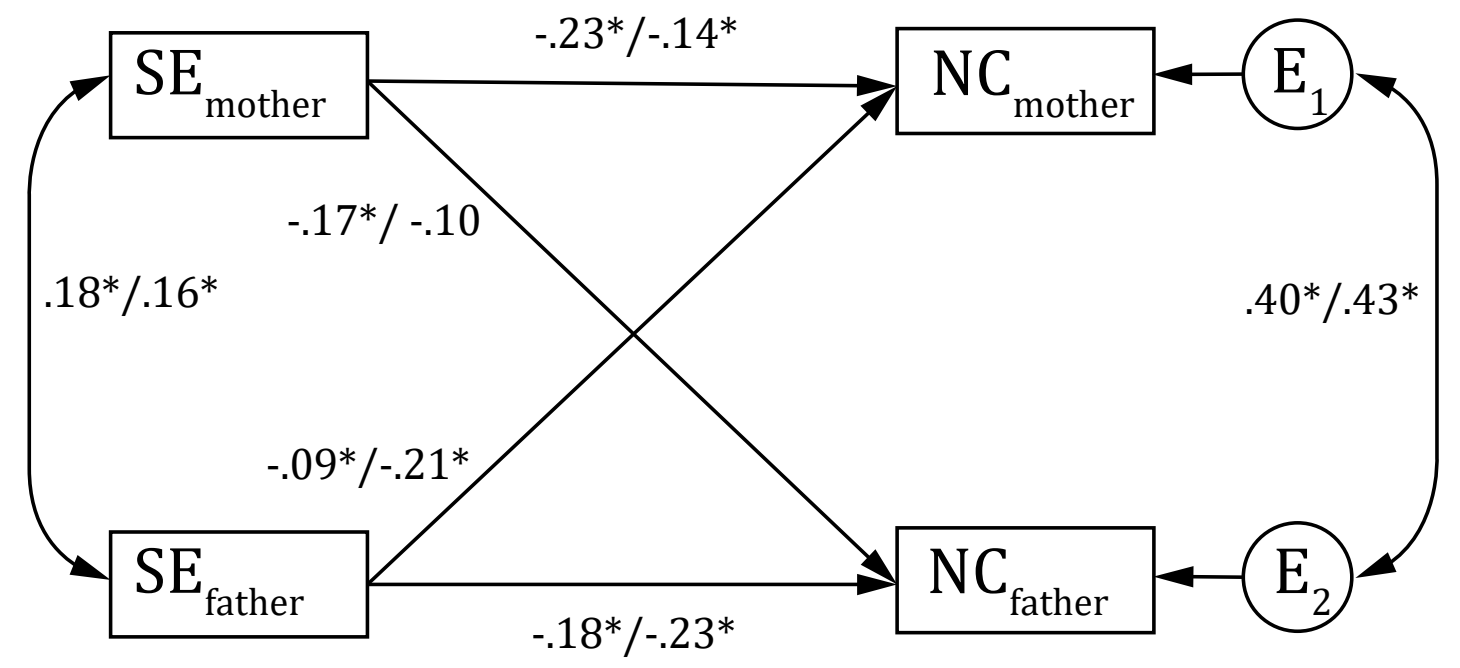


Figure 3. Actor-partner interdependence mediation model of self-esteem (SE) on negative coparenting (NC), with romantic quality (RQ) as mediator. The figure shows standardized estimates. $* p<.05$.

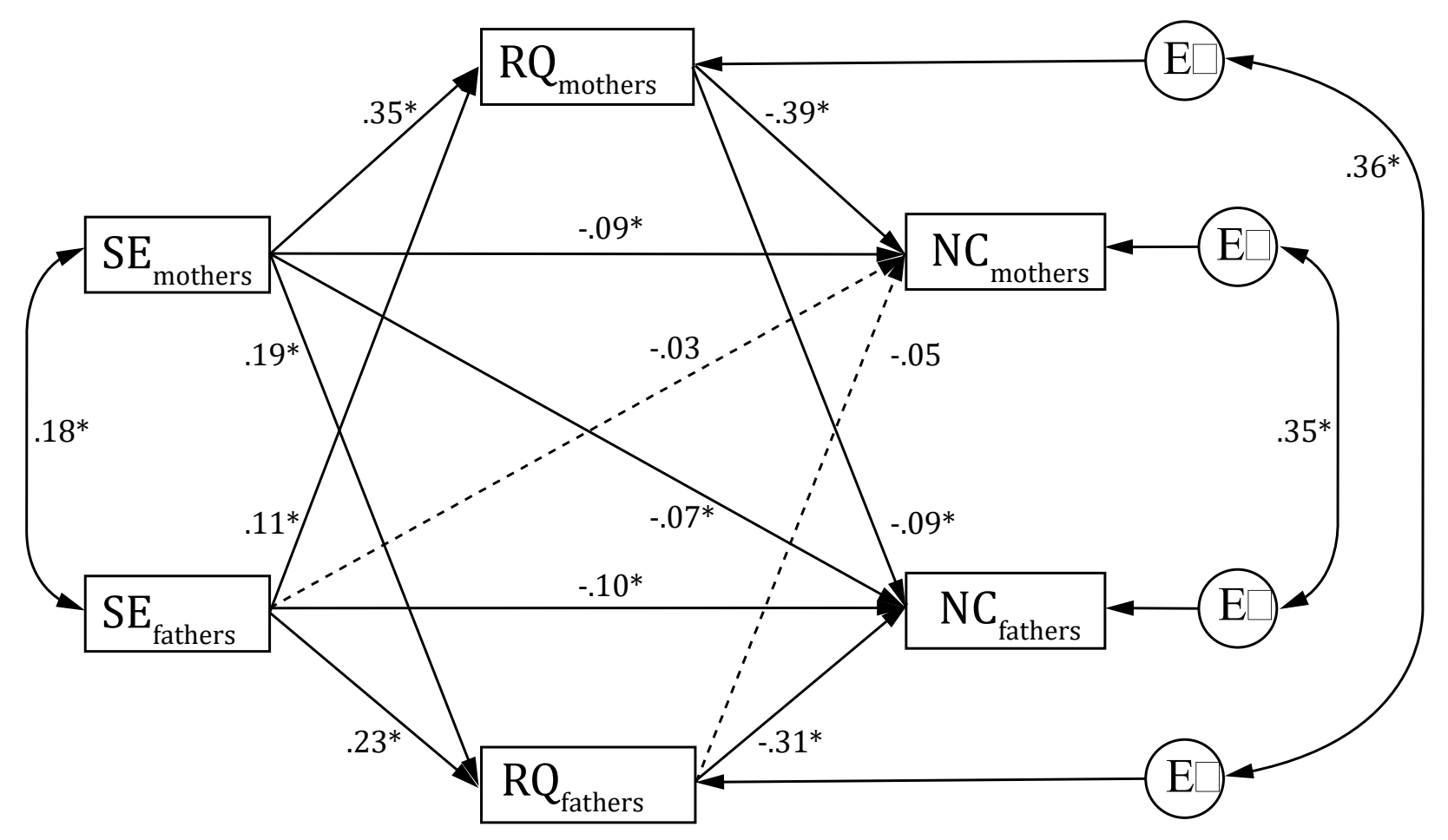

Table 1. Summary of the variables used in Study 1 and Study 2.

\begin{tabular}{|c|c|c|}
\hline Variables & Study 1 & Study 2 \\
\hline Self-esteem & $\begin{array}{l}3 \text { items derived from the } \\
\text { Rosenberg Scale (Rosenberg, } \\
\text { 1965) }\end{array}$ & $\begin{array}{l}10 \text { items, The Rosenberg Scale } \\
\text { (1965) }\end{array}$ \\
\hline Romantic quality & $\begin{array}{l}6 \text { items, adapted from the } \\
\text { Network of Relationships } \\
\text { Inventory (Furman \& } \\
\text { Buhrmester, 1985) }\end{array}$ & $\begin{array}{l}32 \text { items, The Dyadic } \\
\text { Adjustment Scale (DAS; } \\
\text { Spanier, 1976) }\end{array}$ \\
\hline Coparental quality & $\begin{array}{l}3 \text { items adapted from the } \\
\text { Parent Problem Checklist } \\
\text { (Dadds \& Powell, 1991) }\end{array}$ & $\begin{array}{l}11 \text { items, the Coparental Scale } \\
\text { (McHale, 1997) }\end{array}$ \\
\hline
\end{tabular}


Appendices

Table 1

Means, standard deviations, and zero-order correlations between mothers and fathers on self-esteem, romantic quality, and coparental quality in Study 1

\begin{tabular}{|c|c|c|c|c|c|c|c|}
\hline Variables & 1 & 2 & 3 & 4 & 5 & 6 & Mean $(S D)$ \\
\hline 1. Mothers' self-esteem & - & $.18^{*}$ & $.37^{*}$ & $.22^{*}$ & $-.25^{*}$ & $-.19 *$ & $11.45(2.73)$ \\
\hline 2. Fathers' self-esteem & & - & $.17^{*}$ & $.26^{*}$ & $-.12^{*}$ & $-.21 *$ & $12.07(2.36)$ \\
\hline 3. Mothers' romantic quality & & & - & $.42^{*}$ & $-.45^{*}$ & $-.26^{*}$ & $27.48(3.92)$ \\
\hline 4. Fathers' romantic quality & & & & - & $-.24^{*}$ & $-.39 *$ & $26.83(3.62)$ \\
\hline $\begin{array}{l}\text { 5. Mothers' negative } \\
\text { coparenting }\end{array}$ & & & & & - & $.43^{*}$ & $5.37(2.27)$ \\
\hline $\begin{array}{l}\text { 6. Fathers' negative } \\
\text { coparenting }\end{array}$ & & & & & & - & $5.16(1.99)$ \\
\hline
\end{tabular}


Table 2

Means, standard deviations, and zero-order correlations between mothers and fathers on self-esteem, romantic quality, and coparental quality in Study 2

\begin{tabular}{|c|c|c|c|c|c|c|c|c|c|}
\hline Variables & 1 & 2 & 3 & 4 & 5 & 6 & 7 & 8 & $\begin{array}{l}\text { Mean } \\
(S D)\end{array}$ \\
\hline 1. Mothers' self-esteem & - & $.16^{*}$ & $.37^{*}$ & $.26^{*}$ & $-.18^{*}$ & $-.13^{\dagger}$ & $.25^{*}$ & .10 & $\begin{array}{l}41.58 \\
(6.04)\end{array}$ \\
\hline 2. Fathers' self-esteem & & - & $.18^{*}$ & $.34^{*}$ & $-.22^{*}$ & $-.25^{*}$ & .05 & $.14^{*}$ & $\begin{array}{l}42.78 \\
(6.13)\end{array}$ \\
\hline 3. Mothers' romantic quality & & & - & $.66^{*}$ & $-.41^{*}$ & $-.24^{*}$ & $.41^{*}$ & $.21^{*}$ & $\begin{array}{l}115.69 \\
(14.71)\end{array}$ \\
\hline 4. Fathers' romantic quality & & & & - & $-.31^{*}$ & $-.29 *$ & $.26^{*}$ & $.39^{*}$ & $\begin{array}{l}115.35 \\
(14.37)\end{array}$ \\
\hline $\begin{array}{l}\text { 5. Mothers' negative } \\
\text { coparenting }\end{array}$ & & & & & - & $.47^{*}$ & .03 & .02 & $\begin{array}{l}11.68 \\
(3.96)\end{array}$ \\
\hline $\begin{array}{l}\text { 6. Fathers' negative } \\
\text { coparenting }\end{array}$ & & & & & & - & -.04 & .00 & $\begin{array}{l}10.81 \\
(3.84)\end{array}$ \\
\hline $\begin{array}{l}\text { 7. Mothers' positive } \\
\text { coparenting }\end{array}$ & & & & & & & - & $.21^{*}$ & $\begin{array}{l}33.18 \\
(4.01)\end{array}$ \\
\hline $\begin{array}{l}\text { 8. Fathers' positive } \\
\text { coparenting }\end{array}$ & & & & & & & & _. & $\begin{array}{l}31.56 \\
(4.77)\end{array}$ \\
\hline
\end{tabular}

${ }^{\dagger} p<.10 ;^{*} p<.05$. 
Table 3

Effects of self-esteem on negative coparenting with romantic quality as mediator

\begin{tabular}{|c|c|c|c|c|}
\hline \multirow[t]{2}{*}{ Effect } & \multicolumn{2}{|c|}{$\begin{array}{l}\text { Standardized } \\
\text { Estimate }\end{array}$} & $95 \% \mathrm{CI}$ & \multirow[t]{2}{*}{$\begin{array}{l}\text { Percentage of } \\
\text { the Total Effect }\end{array}$} \\
\hline & & Lower & Upper & \\
\hline \multicolumn{5}{|l|}{ Mother Actor Effect } \\
\hline Total Effect & -0.230 & -0.231 & -0.151 & \\
\hline Total IE & -0.145 & -0.142 & -0.099 & 63.0 \\
\hline Actor-Actor IE & -0.135 & -0.134 & -0.090 & 58.7 \\
\hline Partner-Partner IE & -0.010 & -0.018 & 0.001 & 4.3 \\
\hline Direct effect & -0.085 & -0.108 & -0.033 & 37.0 \\
\hline \multicolumn{5}{|l|}{ Father Actor Effect } \\
\hline Total Effect & -0.180 & -0.195 & -0.106 & \\
\hline Total IE & -0.082 & -0.086 & -0.051 & 45.5 \\
\hline Actor-Actor IE & -0.071 & -0.076 & -0.043 & 39.4 \\
\hline Partner-Partner IE & -0.011 & -0.016 & -0.002 & 6.1 \\
\hline Direct effect & -0.098 & -0.124 & -0.041 & 54.5 \\
\hline \multicolumn{5}{|l|}{$\begin{array}{l}\text { Mother Partner } \\
\text { Effect }\end{array}$} \\
\hline Total Effect & -0.088 & -0.135 & -0.033 & \\
\hline Total IE & -0.056 & -0.076 & -0.031 & 63.6 \\
\hline Actor-Partner IE & -0.012 & -0.024 & 0.001 & 13.6 \\
\hline Partner-Actor IE & -0.044 & -0.062 & -0.022 & 50.0 \\
\hline Direct effect & -0.032 & -0.078 & 0.018 & 36.4 \\
\hline \multicolumn{5}{|c|}{ Father Partner Effect } \\
\hline Total Effect & -0.165 & -0.159 & -0.083 & \\
\hline Total IE & -0.091 & -0.085 & -0.048 & 55.2 \\
\hline Actor- Partner IE & -0.032 & -0.039 & -0.008 & 19.4 \\
\hline Partner- Actor IE & -0.059 & -0.057 & -0.030 & 35.8 \\
\hline Direct effect & -0.074 & -0.092 & -0.017 & 44.8 \\
\hline
\end{tabular}

Note. $\mathrm{CI}=$ confidence interval. $\mathrm{IE}=$ indirect effect. Mother partner effect $=$ effect of father's self-esteem on mother's outcome. Detail of mother's actor effect: Total effect = direct effect + actor-actor IE + partner-partner IE $=c^{\prime}+\left(\right.$ amother $\left.{ }^{*} b_{\text {mother }}\right)+\left(\right.$ afather $\left.{ }^{*} b_{\text {father }}\right)=$ 
effect of mother's self-esteem on mother's negative coparenting + (effect of mother's self-esteem on mother's romantic quality * effect of mother's romantic quality on mother's negative coparenting) + (effect of mother's self-esteem on father's romantic quality * effect of father's romantic quality on mother's negative coparenting). Total IE = actor-actor IE + partner-partner IE. 